\title{
Video-assisted thoracoscopic diaphragm plication using a running suture technique is durable and effective
}

\author{
David S. Demos, MD, ${ }^{a}$ Mark F. Berry, MD, ${ }^{a}$ Leah M. Backhus, MD, ${ }^{\mathrm{a}, \mathrm{b}}$ and Joseph B. Shrager, MD $^{\mathrm{a}, \mathrm{b}}$
}

\begin{abstract}
Objective: Surgeons have hesitated to adopt minimally invasive diaphragm plication techniques because of technical limitations rendering the procedure cumbersome or leading to early failure or reduced efficacy. We sought to demonstrate efficacy and durability of our thoracoscopic plication technique using a single running suture.

Methods: We retrospectively reviewed patients who underwent our technique for diaphragm plication since 2008. We used a single, buttressed, double-layered, toand-fro running suture with additional plicating horizontal mattress sutures as needed.
\end{abstract}

Results: Eighteen patients underwent thoracoscopic plication from 2008 to 2015. There were no operative mortalities and 2 unrelated late deaths. Median hospital stay was 3 days (range, 1-12). Atrial fibrillation occurred in 1 patient $(5.5 \%)$, pneumonia occurred in 2 patients $(11 \%)$, reintubation occurred in 1 patient $(5.5 \%)$, and ileus occurred in 1 patient $(5.5 \%)$. Of 14 patients with complete follow-up, median follow-up was 29.4 months (range, 3.4-84.7). Significant increases between preoperative and postoperative pulmonary function tests ( $\%$ predicted values) were found for mean forced expiratory volume in 1 second $(73.5 \% \pm 3.5 \%$ to $88.8 \% \pm 4.5 \%, P=.002)$ and mean forced vital capacity $(70.6 \% \pm 3.5 \%$ to $82.3 \% \pm 3.5 \%, P=.002)$. Preoperative mean Baseline Dyspnea Index was $8.1 \pm 0.7$. Mean Transitional Dyspnea Index 6 months postoperatively was $7.1 \pm 0.6$ (moderate to major improvement). Transitional Dyspnea Index at last contact (median 29.4 months postoperatively) was $7.2 \pm 0.6(P=.38)$. Compared with previously published results, this is at least equivalent.

Conclusions: Thoracoscopic diaphragm plication with a running suture is safe and achieves excellent early and long-term improvements. This addresses technical challenges of tying multiple interrupted sutures by video-assisted thoracoscopic surgery without any apparent compromise to efficacy or durability. ( $\mathrm{J}$ Thorac Cardiovasc Surg 2017;153:1182-8)

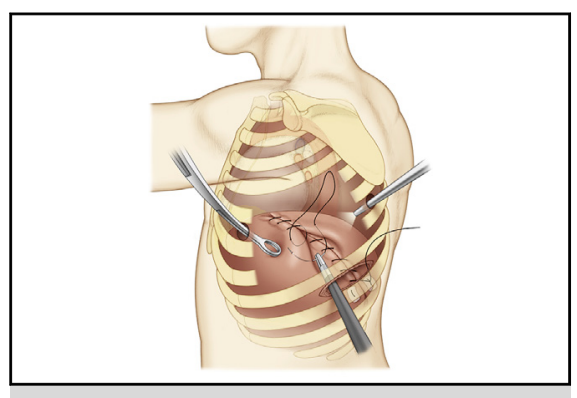

Running suture technique of VATS DP

Central Message

VATS plication for diaphragm paralysis using a single running suture technique is efficient, highly effective, and durable.

\section{Perspective}

DP continues to be most commonly performed by thoracotomy, despite the fact that VATS techniques have equivalent or better results. We present our experience with a simplified, efficient technique using a single, to-and-fro running suture line and establish that this approach is highly effective and durable. This should encourage more surgeons to use VATS for DP.

See Editorial Commentary page 1189.

See Editorial page 1180 .
Diaphragm plication (DP) is a well-established operation that substantially improves dyspnea and objective measures

From the a Division of Thoracic Surgery, Stanford University School of Medicine, Palo Alto; and ${ }^{\text {b}}$ Veterans Affair Palo Alto Health Care System, Palo Alto, Calif. Read at the 42nd Annual Meeting of The Western Thoracic Surgical Association, Waikoloa, Hawaii, June 22-25, 2016.

Institutional Review Board Approval: 35962 on December 10, 2015.

Received for publication June 23, 2016; revisions received Nov 15, 2016; accepted for publication Nov 24, 2016; available ahead of print Jan 10, 2017.

Address for reprints: David S. Demos, MD, Stanford University School of Medicine, Division of Thoracic Surgery, 303 Saturn Terrace, Sunnyvale, CA 94086 (E-mail: ddemosmd@outlook.com).

$0022-5223 / \$ 36.00$

Copyright (c) 2016 by The American Association for Thoracic Surgery

http://dx.doi.org/10.1016/j.jtcvs.2016.11.062 of pulmonary function in patients who are symptomatic from diaphragm paralysis or eventration. ${ }^{1-5}$ During the past 2 decades, minimally invasive approaches to DP have been developed with published case series suggesting that these offer similar improvements as open approaches, while minimizing surgical trauma. ${ }^{6-12}$ The fact that thoracotomy itself is known to reduce diaphragm function

Scanning this QR code will take you to a procedural video for this article. 


$$
\begin{aligned}
& \text { Abbreviations and Acronyms } \\
& \begin{aligned}
\mathrm{BDI} & =\text { Baseline Dyspnea Index } \\
\mathrm{CO}_{2} & =\text { carbon dioxide } \\
\mathrm{DLCO} & =\text { diffusion capacity of carbon monoxide } \\
\mathrm{DP} & =\text { diaphragm plication } \\
\mathrm{FEV} 1 & =\text { forced expiratory volume in } 1 \text { second } \\
\mathrm{FVC} & =\text { forced vital capacity } \\
\mathrm{PFT} & =\text { pulmonary function test } \\
\text { TDI } & =\text { Transitional Dyspnea Index } \\
\text { VATS } & =\text { video-assisted thoracoscopic surgery }
\end{aligned}
\end{aligned}
$$

transiently ${ }^{13,14}$ and that this deficit recovers more quickly after video-assisted thoracoscopic surgery (VATS) than after thoracotomy ${ }^{15}$ is one of several arguments in favor of performing plication in a minimally invasive manner.

However, it has been our impression that many surgeons, even those well experienced with VATS, have been hesitant to adopt minimally invasive DP techniques because of technical demands specific to the plication procedure that may be perceived as difficult to overcome by minimally invasive surgery. One recent article supports the impression that the majority of plications are still done by thoracotomy. ${ }^{16}$ Chief among the issues that may dissuade adoption of VATS DP is that the generally taught open plication technique often relies on placing multiple, interrupted buttressed sutures to minimize the chances that 1 suture pulling through would lead to loss of the entire plication. Performing the procedure by this technique via a VATS approach requires tying multiple knots endoscopically. This can be tedious, even for surgeons who regularly perform VATS lobectomy, and the knots may be less secure.

In 2008, we adopted a modification of a technique of VATS DP first described by Mouroux and colleagues, ${ }^{17}$ which allows creation of a 2-layer imbrication as the main plication, using a single, running polypropylene suture. We retrospectively evaluated the results using this efficient, standardized technique to determine its equivalence to open techniques in terms of early postoperative outcomes. We also collected longer-term outcomes, including patientreported symptoms to test the hypothesis that relying on a single running suture would not compromise results over time.

\section{MATERIALS AND METHODS}

This study was approved by our institutional review board for human subject research. Written informed consent was obtained from each participant. All patients with an elevated hemidiaphragm that persisted for at least 6 months, dyspnea, and restriction on pulmonary function testing (PFTs) were considered for VATS plication. No patients who required additional waiting time to reach a 6-month interval from onset experienced any recovery. Cross-sectional imaging of the chest (and neck if presenting with cervical spine symptoms) was routinely performed. Diaphragmatic fluoroscopy ("Sniff Test") was routinely performed, but a finding of paradoxical cephalad motion on sniff was not required to proceed with plication.

\section{Surgical Technique}

A demonstration of the described procedure can be viewed in Video 1. Patients are positioned in a full lateral decubitus position, but with somewhat less than maximal flexion (to allow some reverse Trendelenburg to be achieved, so that that abdominal contents and diaphragm can gravitate caudally). An orogastric tube is placed to decompress the stomach. Three incisions are made. The main working incision, through which suturing is done, is a $5-\mathrm{cm}$ incision extending posteriorly from the posterior axillary line, placed at the level that the surgeon intends the dome of the diaphragm to sit after the plication is complete (ie, at the diaphragmatic dome's normal resting position at approximately the eighth interspace). The underlying few centimeters of the latissimus dorsi and intercostal muscles are divided, and a soft tissue spreader is placed. The ribs are never spread. A 5-mm camera port is placed 2 intercostal spaces cephalad and 3 to $4 \mathrm{~cm}$ posterior to the working incision. A $1-\mathrm{cm}$ incision is placed at the fifth or sixth intercostal space, anterior axillary line, and is used primarily to pass an instrument with which to depress the diaphragm and to grasp and elevate the tissue off of underlying abdominal structures for each suture bite taken.

Upon entry, the markedly elevated diaphragm will usually nearly completely block the view into the chest through the low, posterior working incision (a "wall of diaphragm" is seen). After depressing the diaphragm (and underlying abdominal contents) gently with a ring clamp placed via the anterior incision, the open pleural space can be seen directly through the working incision, and the folds for the initial plication can begin to be developed. A 40 inch-long, \#1 polypropylene suture on a CT needle is used to begin a suture line directly beneath the working incision, placing the initial bites as far posteriorly a feasible, to within 6 or $7 \mathrm{~cm}$ of the diaphragm's insertion on the ribs. A horizontal mattress bite, buttressed with felt pledgets, is taken between 2 folds of the diaphragm that are approximately $5 \mathrm{~cm}$ apart. These folds are then developed so that they run over the dome of the diaphragm in 2 parallel lines from posterolateral (beneath the working incision) to anteromedial (near the phrenic nerve insertion). The initial mattress suture is hand-tied, leaving a tail long

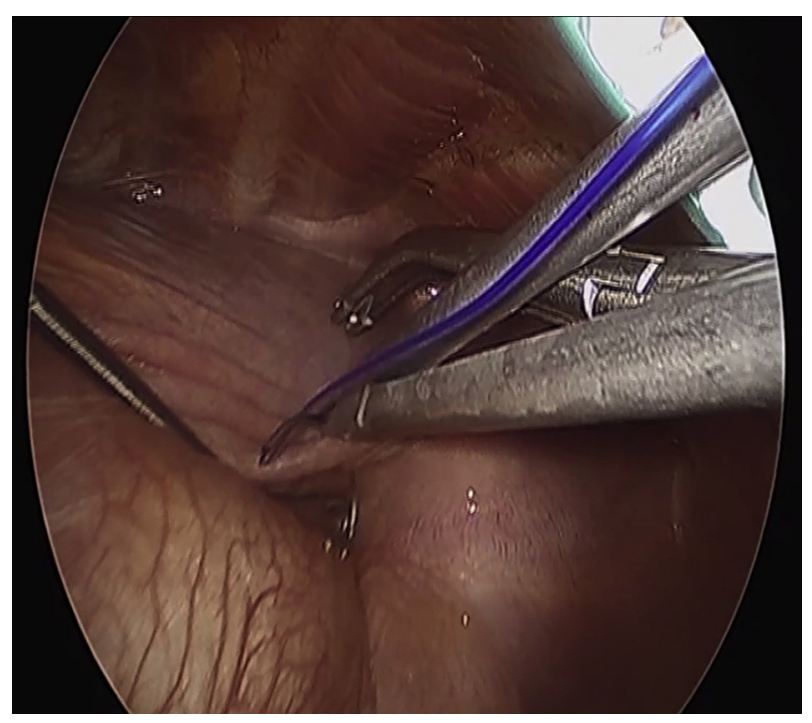

VIDEO 1. Technique of VATS DP using a single 2-layer running suture. Video available at: http://www.jtcvsonline.org/article/S0022-5223(16) 31801-3/addons. 


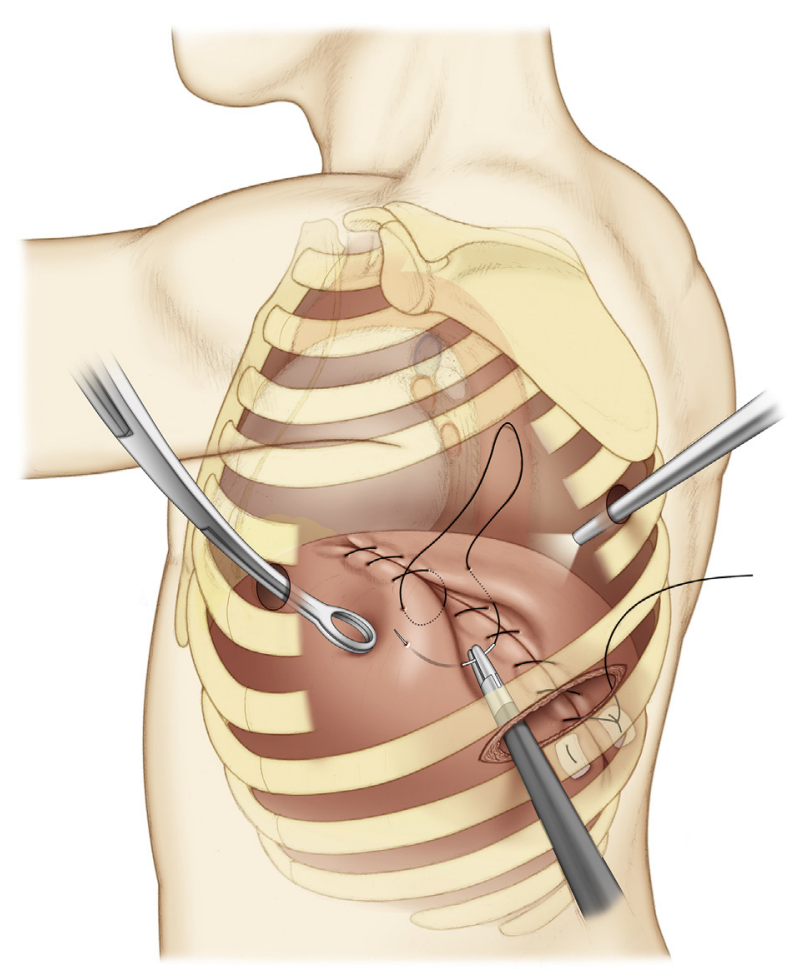

FIGURE 1. Technique of the main DP. The main working incision is in the eighth to ninth interspace. The camera port is 2 interspaces more cephalad, just posterior to the posterior axillary line. The $1-\mathrm{cm}$, anterior assisting incision is in the fifth to sixth interspace, as anteriorly as possible. Pictured are the 2 suture lines of the main plication. The first suture line running toward the anterior cardiophrenic recess (away from the surgeon) has been completed and is now seen returning back toward the working incision. The returning suture line oversews the original suture line, imbricating additional tissue beyond that captured in the first suture line, allowing the surgeon to set the diaphragm tension depending on how much additional tissue he/she chooses to incorporate. Note the free suture hanging from the initial buttressed knot, to which the running suture will be secured after completion of the returning suture line.

enough to comfortably tie to subsequently. The suture is then run in continuous fashion anteromedially, imbricating the muscle between the 2 folds until it reaches to within 6 to $7 \mathrm{~cm}$ of the anteromedial diaphragm insertion. Each bite takes approximately $2 \mathrm{~cm}$ of muscle within it. As the running suture line is developed, the diaphragm moves progressively lower, and the exposure thus becomes progressively better.

At the anteromedial end, the running suture is reversed and captures 2 new folds taken a few $\mathrm{cm}$ beyond the initial suture line (Figure 1). The width of this second imbrication will depend on the subjective assessment of the surgeon as to how much more the diaphragm needs to be depressed to achieve an ideal result; generally, an additional 2 to $3 \mathrm{~cm}$ is imbricated on each side of the initial suture line. Throughout, the diaphragm is gently depressed with the ring clamp from anteriorly. When the returning continuous suture reaches the initially placed horizontal mattress suture, it is tied to the tail of that initial suture over another felt pledget.

At this point, the surgeon can assess the adequacy of the plication. The goal is moderate tension and a normal diaphragm position, without so much tension that the sutures might pull through. In most cases, we have opted to place 1 to 2 additional, individual buttressed horizontal mattress sutures in areas where the diaphragm remains mildly redundant. These are placed to create localized imbrications that run in the opposite direction to the main imbrication, so as not to create additional tension on the main imbrication. Intercostal nerve blocks covering all of the incisions are placed with Marcaine. A $24 \mathrm{~F}$ chest tube is placed to $-10 \mathrm{~cm}$ of suction.

In 2 patients in whom the colon was dangerously positioned above the liver on the right (Chilaiditi Syndrome), we inserted a single laparoscopic port during the procedure to allow visualization from below to be certain that our plicating sutures would not injure the colon. In cases with normal anatomy, bites are taken somewhat more carefully on the left than on the right to be certain to avoid the underlying spleen and stomach. The preoperative computed tomogram is always studied for the location of these organs.

\section{Follow-up}

Patients were routinely seen for in-person office visits at short-term (24 weeks) and midterm ( $\sim 7$ months) follow-up. PFTs were measured at or close to the time of the midterm follow-up (at a median of 6.6 months [range, 1.9-26.5] postoperatively).

\section{Dyspnea Scores}

The Baseline Dyspnea Index (BDI) and the Transitional Dyspnea Index (TDI), each originally developed by Mahler and colleagues in $1984,{ }^{18}$ were used to quantify and track dyspnea over time. The BDI is used as a discriminative instrument to measure dyspnea at a single point in time (ie, at baseline), whereas the TDI is designed to measure changes in dyspnea from the baseline state. These surveys were originally meant to be administered by a trained interviewer. However, a self-administered version of these surveys was developed by Mahler and colleagues ${ }^{19}$ and validated as reliable and concordant with the original method. The BDI (Table 1) asks patients to estimate the impact of their dyspnea, on a scale of 0 to 4 , from 3 separate points of view, and thus yielding a maximum severity of 12 . The TDI (Table 2) asks patients to estimate, on a scale from -3 to +3 , the degree of worsening or improvement in their dyspnea from the same 3 points of view, and it thus yields a maximum improvement of +9 or deterioration of -9 .

In this study, patients were contacted via US mail for informed consent to participate in the study and to distribute the dyspnea surveys. They were subsequently contacted by telephone to review the survey and answer any questions if needed. They were asked to recall and record their dyspnea symptoms using these survey instruments at baseline (preoperatively), 6 months postoperatively, and currently (at the time of filling out the survey). The dyspnea surveys were then completed and returned via US mail.

\section{Statistical Analysis}

PFT parameters forced expiratory volume in 1 second (FEV1), forced vital capacity (FVC), and diffusion capacity of carbon monoxide (DLCO) from before surgery and at follow-up postoperatively were compared. Transitional dyspnea scores at 6 months postoperatively and at last contact were compared. Continuous variables were compared using paired $t$ test, and ordinal survey data was compared using the Wilcoxon signed-rank test.

\section{RESULTS}

Forty patients underwent DP at Stanford University Hospital from 2008 to 2015. Twenty-two of these procedures were performed by VATS according to surgeon preference and patient characteristics. Eighteen of the VATS plications were completed by the described technique and were included in this study. These 18 patients constituted all of the isolated DPs (ie, plications not performed concurrently with another procedure, such as lung or thymic resection) performed by the senior author over the study period. The other 4 VATS 
TABLE 1. Baseline Dyspnea Index survey

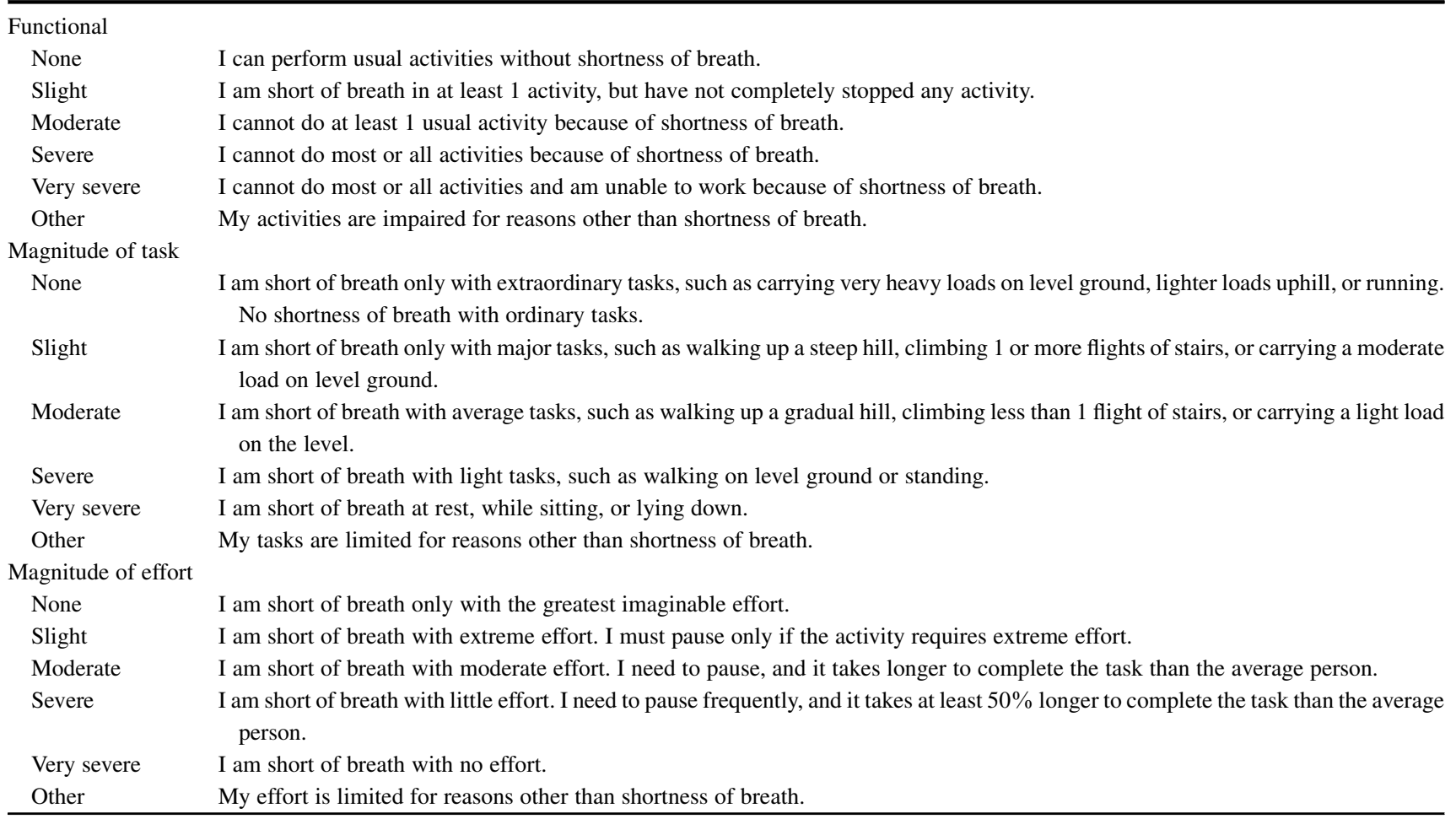

plications were performed by other surgeons by a variety of other techniques. These 18 patients were used in the analysis of early complications.

Of these 18 patients, there were 2 late deaths unrelated to the plication. One patient died of congestive heart failure, and 1 patient died of progressive malignancy (his plication was performed because of metastatic melanoma infiltrating his phrenic nerve high in the chest). The patient with heart failure died 3 years postoperatively. The patient with malignancy died 5 months postoperatively. Neither of these patients completed follow-up PFTs. An additional 2 patients were lost to follow-up and thus did not have postoperative data to analyze. This left 14 patients available for postoperative analysis including PFT and symptomatic follow-up.

Preoperative characteristics are shown in Table 3. On fluoroscopy with sniff testing, all but 4 patients had paradoxical elevation of the diaphragm with sniff, and these 4 patients each had varying degrees of subjectively reduced diaphragmatic downward displacement with sniff. In addition to the main, to-and-fro, double-layer plication with a single Prolene suture, a mean of $2.1 \pm 0.4$ additional horizontal mattress sutures were placed subsequently to achieve optimal diaphragm tension.

There were no 90-day mortalities. Median hospital stay was 3 days (range, 1-12 days). Median chest tube duration was 2 days (range, 0-10). Postoperative complications were uncommon, with atrial fibrillation in 1 patient $(5.5 \%)$, pneumonia in 2 patients $(11 \%)$, reintubation in 1 patient
$(5.5 \%)$, and ileus in 1 patient $(5.5 \%)$. Fifteen patients $(83.3 \%)$ had no complications. The 1 patient with a length of stay of 12 days developed a pneumonia requiring reintubation and intensive care unit admission. In all cases, the diaphragm was dramatically lower on all postoperative images while in the hospital and on follow-up imaging at approximately 3 weeks and 7 months after the procedure.

Median total follow-up time (to the time of dyspnea survey) was 29.4 months (range, 3.4-84.7; mean, 36.6). Postoperative PFTs were available in $14(87.5 \%)$ of the 16 surviving patients (Table 4 ), and they were performed at a median of 6.6 months (range, 1.9-26.5; mean, 10.6) postoperatively. Statistically significant increases between preoperative and postoperative PFTs ( $\%$ predicted values) were found for mean FEV1 $(73.5 \% \pm 3.5 \%$ to $88.8 \% \pm 4.5 \%$, $P=.002)$ and mean FVC $(70.6 \% \pm 3.5 \%$ to $82.3 \% \pm 3.5 \%, P=.002)$. An observed increase between mean preoperative and postoperative DLCO from $80.3 \% \pm 5.6 \%$ predicted to $84.6 \% \pm 9.4 \%$ predicted was not statistically significant $(P=.6)$. Inspiratory force was measured only rarely and thus is not available for analysis.

Dyspnea survey scores were available in $13(81.3 \%)$ of the 16 surviving patients (Table 5). All of the TDI scores were obtained at a median of 29.4 months (range, 3.484.7; mean, 36.6), well beyond when PFTs were obtained. Preoperative mean BDI score was $8.08 \pm 0.7$ (on the scale where 12 represents the most severe dyspnea). The patientreported mean TDI score 6 months postoperatively was 
TABLE 2. Transitional Dyspnea Index survey

\begin{tabular}{ll}
\hline Functional & \\
+3 (major) & Improvement \\
+2 (moderate) & \\
+1 (minor) & No change \\
0 (no change) & Deterioration \\
-1 (minor) & \\
-2 (moderate) & \\
-3 (major) & \\
Magnitude of task & Improvement \\
+3 (major) & \\
+2 (moderate) & \\
+1 (minor) & No change \\
0 (no change) & Deterioration \\
-1 (minor) & \\
-2 (moderate) & \\
-3 (major) & \\
Magnitude of effort & Improvement \\
+3 (major) & \\
+2 (moderate) & \\
+1 (minor) & No change \\
0 (no change) & Deterioration \\
-1 (minor) & \\
-2 (moderate) & \\
-3 (major) & \\
\hline
\end{tabular}

$7.1 \pm 0.6$, representing a moderate to major improvement in all 3 subcategories contained within the TDI. The repeat mean TDI at last contact (median, 29.4 months postoperatively) was $7.2 \pm 0.6$, unchanged from at 6 months postoperatively $(P=.36)$. The symptomatic benefits of the plication were stable in the long term.

In Table 6, we compare our results with the outcomes reported in the literature. We included all studies published within the last 15 years with at least 10 patients. This produced 6 studies: 1 using laparoscopy, 2 using thoracoscopy, and 3 using thoracotomy. Follow-up was variable, between 1 year and 10 years. PFT and dyspnea survey results are presented in Table 6.

TABLE 3. Preoperative characteristics

\begin{tabular}{ll}
\hline $\mathrm{n}$ & 18 \\
Age, $\mathrm{y}$ & $61 \pm 11$ \\
Male:female & $13: 5$ \\
Right:left & $11: 7$ \\
Cause & \\
$\quad$ Idiopathic & $9(50 \%)$ \\
$\quad$ Iatrogenic & $7(39 \%)$ \\
$\quad$ Malignancy & $1(6 \%)$ \\
$\quad$ Cervical spondylosis & $1(6 \%)$ \\
Sniff test result & \\
$\quad$ Paradoxical motion & $11(61 \%)$ \\
$\quad$ Reduced contractility & $3(17 \%)$ \\
Eventration only & $1(6 \%)$ \\
\hline
\end{tabular}

TABLE 4. Pulmonary function test results

\begin{tabular}{lcccc}
\hline \multicolumn{1}{c}{ Parameter } & Preoperative & Postoperative* $^{*}$ & $\begin{array}{c}\% \\
\text { change }\end{array}$ & $\begin{array}{c}\boldsymbol{P} \\
\text { value }\end{array}$ \\
\hline FVC (\% predicted) & $70.6 \pm 3.5$ & $82.3 \pm 3.5$ & +16.5 & .002 \\
FEV1 (\% predicted) & $73.5 \pm 3.5$ & $88.8 \pm 4.5$ & +20.8 & .002 \\
DLCO (\% predicted) & $80.3 \pm 5.6$ & $84.6 \pm 9.4$ & +4.3 & .6 \\
\hline
\end{tabular}

$F V C$, Forced vital capacity; FEVI, forced expiratory volume in 1 second; $D L C O$, diffusion capacity of carbon monoxide. *Postoperative PFTs were performed at a median of 6.6 months postoperatively.

\section{DISCUSSION}

DP is a well-established effective treatment for diaphragm paralysis and eventration that produces clear postoperative improvements in both symptoms and in objective measures of pulmonary and respiratory muscle function. This procedure traditionally has been approached by open thoracotomy, and the majority of surgeons continue to perform the operation in this way, despite increasingly widespread experience with VATS, even for complex procedures. ${ }^{16}$ The reasons for this are likely as follows: (1) The condition is uncommon, and because of the lack of broad awareness of this effective therapy, even patients in whom the diagnosis is made are uncommonly referred to surgeons; (2) because of the rarity, few surgeons have experience performing open plication and even fewer have experience with VATS plication, thus limiting the potential for the procedure's technical aspects to be developed over time; and (3) there are potential technical limitations that make it challenging to apply the traditional open technique to VATS plication.

Open DP typically uses multiple, interrupted, pledgetted mattress sutures to achieve plication. In this way, failure of 1 suture does not result in failure of the entire plication. Because endoscopic knot-tying is somewhat cumbersome and tedious, using this traditional technique via a VATS approach is not particularly appealing. Diaphragm surgery is already moderately difficult by VATS because of the inherent angular constraints of thoracoscopy for basilar chest surgery. The elevated position of the diaphragm in the situation of paralysis can make appropriate VATS port placement tricky. It also may be that the magnification of VATS makes it difficult to estimate the ideal final level at which one wants to place the diaphragm and to create the optimal degree of tension for a plication. Carbon dioxide

TABLE 5. Dyspnea survey results

\begin{tabular}{lc}
\hline \multicolumn{1}{c}{ Survey } & Mean value \\
\hline BDI & $8.1 \pm 0.7$ (moderate-severe \\
& impairment) \\
TDI - 6 mo & $7.1 \pm 1.9 / 9$ (moderate-major $\quad P=.36$ \\
& improvement) \\
TDI - mean follow-up 29.4 mo & $\begin{array}{l}7.2 \pm 2.4 / 9 \text { (moderate-major } \\
\end{array}$ \\
\hline
\end{tabular}

$B D I$, Baseline Dyspnea Index; TDI, Transitional Dyspnea Index. 
TABLE 6. Comparison of outcomes after diaphragm plication

\begin{tabular}{|c|c|c|c|c|c|c|c|}
\hline Author (Ref) & Year & $\mathbf{N}$ & Follow-up & PFT follow-up & \multicolumn{3}{|c|}{$\%$ Improvement } \\
\hline \multicolumn{5}{|l|}{ Transthoracic (open) } & FEV1 & FVC & \\
\hline Higgs and colleagues $^{2}$ & 2002 & 19 & $10 \mathrm{y}$ & $10 \mathrm{y}$ & 11.8 & & \\
\hline Versteegh and colleagues ${ }^{3}$ & 2007 & 22 & $5 \mathrm{y}$ & $5 \mathrm{y}$ & 10.9 & 12.9 & TDI score: +5.69 \\
\hline Calvinho and colleagues ${ }^{4}$ & 2009 & 20 & $5 \mathrm{y}$ & $5 \mathrm{y}$ & 15.0 & 11.4 & \\
\hline \multicolumn{8}{|l|}{ VATS plication } \\
\hline \multirow[t]{2}{*}{ Mouroux and colleagues $^{6}$} & 2005 & 10 & $1 \mathrm{y}$ & $1 \mathrm{y}$ & 22.9 & & \\
\hline & & 6 & $5 \mathrm{y}$ & $5 \mathrm{y}$ & 25.0 & & \\
\hline Freeman and colleagues ${ }^{9}$ & 2009 & 41 & $4 y$ & $4 y$ & 21.0 & & \\
\hline $\begin{array}{l}\text { Demos ad colleagues } \\
\text { (current study) }\end{array}$ & 2016 & 14 & $2.5 \mathrm{y}$ & $7 \mathrm{mo}$ & 20.8 & 16.5 & TDI score: +7.2 \\
\hline \multicolumn{8}{|l|}{ Laparoscopic plication } \\
\hline \multirow[t]{2}{*}{ Groth and colleagues $^{12}$} & 2010 & 25 & $1 \mathrm{mo}$ & $1 \mathrm{mo}$ & 12.8 & 10.3 & \\
\hline & & & $1 \mathrm{y}$ & $1 \mathrm{y}$ & 7.4 & 3.0 & \\
\hline
\end{tabular}

All studies in past 15 years with at least 10 patients were included. PFT, Pulmonary function test; $F E V 1$, forced expiratory volume in 1 second; FVC, forced vital capacity; TDI, Transitional Dyspnea Index; VATS, video-assisted thoracoscopic surgery.

$\left(\mathrm{CO}_{2}\right)$ insufflation has been used by some to address the issues of visualization by creating diaphragm depression.

The running suture, 3 -incision technique, as described in the current article, eliminates several of these concerns and provides the thoracic surgical community with a reliable, standardized way in which to perform DP minimally invasively. Our technique avoids the need for $\mathrm{CO}_{2}$, simplifying the procedure and potentially leading to cost-savings because there is no need for commercial laparoscopic ports and consumption of $\mathrm{CO}_{2}$. However, there is reasonable concern that a running suture could fail early or over time, leading to less durable results. Therefore, we sought to determine whether this technique compromises early or late outcomes.

A running suture technique with VATS was first proposed by Mouroux and colleagues ${ }^{17}$ in 1996 . Their subsequent experience was published in 2005, and this was the first series of VATS plication that reported outcomes. ${ }^{6}$ The Mouroux technique involves 2 separate running sutures to create 4 rows of progressive plication. We adapted this technique to require only a single suture, running toand-fro, which can be tied down directly beneath the access incision with a traditional, hand-placed knot that the surgeon can be confident is secure. We also placed a mean of 2 separate horizontal mattress sutures to tighten up areas that still appeared mildly redundant after the main line of plication. These sutures may require endoscopic tying, but tying only 1 or 2 sutures in this way adds little time to the procedure, and only a small portion of the plication is then dependent on endoscopically tied knots.

We show that this technique can be carried out with no early or late failures and with little early postoperative morbidity, zero mortality, and a median length of stay of 3 days. Midterm objective improvements include a $16.5 \%$ increase in FVC, 20.8\% increase in FEV1, 5.4\% increase in DLCO (nonsignificant), and 7.3-point symptomatic improvement on TDI (moderate to major improvement). Critically, we demonstrate that there is persistent improvement in the TDI score, without any fall-off, over a median follow-up time to survey completion of 2.5 years. These results establish that this running suture technique yields durable symptomatic results and suggest that the fear of failure due to the suture pulling through tissue are unfounded. We agree with Mouroux and colleagues ${ }^{17}$ that a running suture technique with a monofilament suture likely allows tension to be spread out evenly over the length of the suture line, thus reliably preventing tearing through and failure of the plication.

When compared with previously published functional results after plication performed by thoracotomy and laparoscopy as in Table 6 (acknowledging the difficulty of drawing valid comparisons across studies), our outcomes seem to be superior. When compared with previously published results after VATS plication, our outcomes seem to be similar. Although there is a small group of previous articles 6,9 reporting longer-term outcomes after VATS techniques of plication, Freeman and colleagues ${ }^{9}$ used an interrupted U-stitch technique and not a running suture technique; Mouroux and colleagues ${ }^{6}$ reported long-term results in only 6 of 16 patients in their series.

\section{Study Limitations}

First, this is a single-center, retrospective, noncontrolled study. As such, the results should be cautiously interpreted in application to a broader patient and surgeon population. Second, the small sample size due to the rare nature of this disease limits the strength of the conclusions one can draw. Third, an element of recall bias may play a role in the subjective dyspnea survey results because of the retrospective manner in which the dyspnea surveys were administered. However, we think that patients generally have a high capability to recall how their dyspnea symptoms have changed over time. 


\section{CONCLUSIONS}

VATS DP using mainly a single, to-and-fro, running, double-layer monofilament suture allows expedient, effective DP with extremely low morbidity and zero surgeryrelated mortality. The objective improvements achieved in pulmonary function seem to be better than those achieved by thoracotomy or laparoscopy at 6 months postoperatively, and they seem to be equal to those achieved by other VATS techniques that have been reported. Further, symptomatic improvements persist over a median follow-up of 2.5 years, mitigating concern that achieving plication with a single, running suture would not be durable.

\section{Conflict of Interest Statement}

Authors have nothing to disclose with regard to commercial support.

\section{References}

1. Graham DR, Kaplan D, Evans CC, Hind CR, Donnelly RJ. Diaphragmatic plication for unilateral diaphragmatic paralysis: a 10-year experience. Ann Thorac Surg. 1990;49:248-52.

2. Higgs SM, Hussain A, Jackson M, Donnelly RJ, Berrisford RG. Long term results of diaphragmatic plication for unilateral diaphragm paralysis. Eur J Cardiothorac Surg. 2002;21:294-7.

3. Versteegh MI, Braun J, Voigt PG, Bosman DB, Stolk J, Rabe KF, et al. Diaphragm plication in adult patients with diaphragm paralysis leads to long-term improvement of pulmonary function and level of dyspnea. Eur J Cardiothorac Surg. 2007;32:449-56.

4. Calvinho P, Bastos C, Bernardo JE, Eugénio L, Antunes MJ. Diaphragmatic eventration: long-term follow-up and results of open-chest plicature. Eur J Cardiothorac Surg. 2009;36:883-7.

5. Celik S, Celik M, Aydemir B, Tunckaya C, Okay T, Dogusoy I. Long-term results of diaphragmatic plication in adults with unilateral diaphragm paralysis. J Cardiothorac Surg. 2010;5:111.

6. Mouroux J, Venissac N, Leo F, Alifano M, Guillot F. Surgical treatment of diaphragmatic eventration using video-assisted thoracic surgery: a prospective study. Ann Thorac Surg. 2005;79:308-12.

7. Suzumura Y, Terada Y, Sonobe M, Nagasawa M, Shindo T, Kitano M. A case of unilateral diaphragmatic eventration treated by plication with thoracoscopic surgery. Chest. 1997;112:530-2.
8. Hwang Z, Shin JS, Cho YH, Sun K, Lee IS. A simple technique for the thoracoscopic plication of the diaphragm. Chest. 2003;124:376-8.

9. Freeman RK, Van Woerkom J, Vyverberg A, Ascioti AJ. Long-term follow-up of the functional and physiologic results of diaphragm plication in adults with unilateral diaphragm paralysis. Ann Thorac Surg. 2009;88:1112-7.

10. Huttl TP, Wichmann MW, Reichart B, Geiger TK, Schildberg FW, Meyer G. Laparoscopic diaphragmatic plication: long-term results of a novel surgical technique for postoperative phrenic nerve palsy. Surg Endosc. 2004;18: 547-51.

11. Groth SS, Andrade RS. Diaphragmatic eventration. Thorac Surg Clin. 2009;19: 511-9.

12. Groth SS, Rueth NM, Kast T, D'Cunha J, Kelly RF, Maddaus MA, et al. Laparoscopic diaphragm plication for diaphragmatic paralysis and eventration: an objective evaluation of short- and mid-term results. J Thorac Cardiovasc Surg. 2010;139:1452-6.

13. Melendez JA, Alagesan R, Reinsel R, Weissman C, Burt M. Postthoracotomy respiratory muscle mechanics during incentive spirometry using respiratory inductance plethysmography. Chest. 1992;101:432-6.

14. Maeda H, Nakahara K, Ohno K, Kido T, Ikeda M, Kawashima Y. Diaphragm function after pulmonary resection: relationship to postoperative respiratory failure. Am Rev Respir Dis. 1988;137:678-81.

15. Nomori H, Ohtsuka T, Horio H, Naruke T, Suemasu K. Difference in the impairment of vital capacity and 6-minute walking after a lobectomy performed by thoracoscopic surgery, an anterior limited thoracotomy, an anteroaxillary thoracotomy, and a posterolateral thoracotomy. Surg Today. 2003:33:7-12

16. Rombolá CA, Genovés Crespo M, Tárraga López PJ, García Jiménez MD, Honguero Martínez AF, León Atance P, et al. Is video-assisted thoracoscopic diaphragmatic plication a widespread technique for diaphragmatic hernia in adults? Review of the literature and results of a national survey. Cir Esp. 2014; 92:453-62.

17. Mouroux J, Padovani B, Poirier NC, Benchimol D, Bourgeon A, Deslauriers J, et al. Technique for the repair of diaphragmatic eventration. Ann Thorac Surg. 1996;62:905-7.

18. Mahler DA, Weinberg DH, Wells CK, Feinstein AR. The measurement of dyspnea: contents, interobserver agreement, and physiologic correlates of two new clinical indexes. Chest. 1984;85:751-8.

19. Mahler DA, Ward J, Fierro-Carrion G, Waterman LA, Lentine TF, MejiaAlfaro R, et al. Development of self-administered versions of modified baseline and transition dyspnea indexes in COPD. COPD. 2004;1:165-72.

Key Words: minimally invasive diaphragm plication running suture technique, video-assisted thoracoscopic surgery, thoracoscopy eventration 